\title{
BMJ Open Effects of actual and imagined music- cued gait training on motor functioning and brain activity in people with multiple sclerosis: protocol of a randomised parallel multicentre trial
}

\author{
Barbara Seebacher (D) , ${ }^{1,2}$ Birgit Helmlinger, ${ }^{3,4}$ Daniela Pinter, ${ }^{3,4}$ Rainer Ehling, ${ }^{2,5}$ \\ Harald Hegen, ${ }^{1}$ Stefan Ropele, ${ }^{3}$ Gernot Reishofer, ${ }^{6}$ Christian Enzinger, ${ }^{7}$ \\ Christian Brenneis, ${ }^{2,5}$ Florian Deisenhammer $^{1}$
}

To cite: Seebacher B, Helmlinger B, Pinter D, et al. Effects of actual and imagined music-cued gait training on motor functioning and brain activity in people with multiple sclerosis: protocol of a randomised parallel multicentre trial. BMJ Open 2022;12:e056666. doi:10.1136/ bmjopen-2021-056666

- Prepublication history and additional supplemental material for this paper are available online. To view these files, please visit the journal online (http://dx.doi.org/10.1136/ bmjopen-2021-056666)

Received 21 August 2021 Accepted 25 January 2022
Check for updates

(c) Author(s) (or their employer(s)) 2022. Re-use permitted under CC BY-NC. No commercial re-use. See rights and permissions. Published by BMJ.

For numbered affiliations see end of article.

Correspondence to

Dr Barbara Seebacher;

barbara.seebacher@i-med.ac.at

\section{ABSTRACT}

Introduction Motor imagery (MI) refers to the mental rehearsal of a physical action without muscular activity. Our previous studies showed that MI combined with rhythmic-auditory cues improved walking, fatigue and quality of life $(\mathrm{Q} \mathrm{L})$ in people with multiple sclerosis (pwMS). Largest improvements were seen after music and verbally cued MI. It is unclear whether actual cued gait training achieves similar effects on walking as cued MI in pwMS. Furthermore, in pwMS it is unknown whether any of these interventions leads to changes in brain activation. The purpose of this study is therefore to compare the effects of imagined and actual cued gait training and a combination thereof on walking, brain activation patterns, fatigue, cognitive and emotional functioning in pwMS.

Methods and analysis A prospective double-blind randomised parallel multicentre trial will be conducted in 132 pwMS with mild to moderate disability. Randomised into three groups, participants will receive music, metronome and verbal cueing, plus Ml of walking (1), MI combined with actual gait training (2) or actual gait training (3) for $30 \mathrm{~min}, 4 \times$ per week for 4 weeks. Supported by weekly phone calls, participants will practise at home, guided by recorded instructions. Primary endpoints will be walking speed (Timed 25-Foot Walk) and distance (2 min Walk Test). Secondary endpoints will be brain activation patterns, fatigue, QoL, Ml ability, anxiety, depression, cognitive functioning, music-induced motivation-to-move, pleasure, arousal and self-efficacy. Data will be collected at baseline, postintervention and 3-month follow-up. MRI reference values will be generated using 15 matched healthy controls.

Ethics and dissemination This study follows the Standard Protocol Items: Recommendations for Interventional Trials-PRO Extension. Ethical approval was received from the Ethics Committees of the Medical Universities of Innsbruck (1347/2020) and Graz (33-056 ex 20/21), Austria. Results will be disseminated via national and international conferences and published in peerreviewed journals.

Trial registration number DRKS00023978.

\section{Strengths and limitations of this study}

- This is the first prospective double-blind randomised parallel multicentre trial to investigate the effects of imagined and actual gait training with music, metronome and verbal cueing versus a combination thereof in people with multiple sclerosis (MS).

- The intervention of this study was informed by previous study results and involvement of patients with MS.

- Study participants with MS will receive close individual telephone support of their home-based training to facilitate their motor learning and adherence.

- Semi-structured telephone interviews will assist in gaining insight into participants' perspectives of the intervention.

- Subjective and objective assessments and functional MRI will be used as outcome parameters.

\section{INTRODUCTION}

Multiple sclerosis (MS) is a chronic inflammatory demyelinating disease of the central nervous system leading to disability accumulation. People with MS (pwMS) frequently have impairment in motor, sensory, visual and other functional systems. ${ }^{1}$ Walking impairment and fatigue contribute to a limitation in quality of life (QoL).$^{2-4}$ Motor imagery $(\mathrm{MI})^{5}$ and rhythmic-auditory stimulation, or cueing ${ }^{6-9}$ are specific physiotherapy interventions. Rhythmic-auditory cues facilitate cyclical movements, predominantly gait, ${ }^{6}$ which can be provided either by a metronome or music beat, ${ }^{78}$ a combination thereof, ${ }^{9}$ or by rhythmic verbal cues. ${ }^{10}{ }^{11}$ Cued walking training has been found to improve walking in people with neurological diseases including MS. ${ }^{12-16}$ The stimulation leads 
to interactions between sensory and motor processes, referred to as sensorimotor interaction. ${ }^{17}$

MI is the mental execution of a movement without its actual performance ${ }^{18}$ and MI of walking activates brain areas similar to those in actual walking. ${ }^{19}$ Different imagery models exist and include individual and group MI, with or without physical practice. ${ }^{21}$ Jeannerod has distinguished between an internal and an external MI perspective. ${ }^{22}$ Further, a visual and a kinaesthetic MI mode have been described. ${ }^{23}$ Persons imagine watching themselves moving with visual MI, with the kinaesthetic mode, they feel themselves moving. ${ }^{24}$

Few small studies have explored rhythmic-cued gait training ${ }^{1516}$ or MI of walking ${ }^{2526}$ in pwMS, showing promising preliminary results. Results from our previous work showed superior effects of music and verbally cued MI over non-cued MI on walking, fatigue and QoL. ${ }^{27}{ }^{28}$ So far, no studies have compared the effects of cued MI on walking and cued gait training or a combined cued MI and gait training in pwMS. Building on the promising results of our previous studies, we furthermore want to learn whether observed behavioural changes are reflected by changes in brain activation patterns. MRI has been suggested to contribute to the understanding of mechanisms behind motor deficits and functional recovery in pwMS. ${ }^{29} 30$ So far, functional MRI (fMRI) studies on motor rehabilitation in pwMS are scarce and, ${ }^{29} 31$ to our knowledge, brain activation changes due to specific walking training need to be further explored in pwMS. Extending the study by Tavazzi et $a l^{29}$ who showed a reduced extent of the widespread brain activation during a motor task (plantar dorsiflexion) after gait rehabilitation in pwMS, we will assess potential changes in brain activation associated with cued MI and/or cued gait training. In line, beneficial training might be associated with an increased activation of the primary motor areas, along with decreased activation outside the sensorimotor network (eg, frontal areas). ${ }^{29} 3233$ We expect that MI training leads to similar neural reorganisation patterns as actual practice. ${ }^{34}$

Therefore, the purpose of this study is to determine the effects of actual and imagined rhythmic-cued gait training vs their combination on walking, cognitive and emotional functioning in pwMS. Further aims are to compare brain activation changes during a motor or MI task between groups and determine which changes are specifically associated with improvements in gait function.

\section{ALTERNATIVE HYPOTHESES}

H1: All trainings will significantly improve walking, fatigue, QoL, emotional and cognitive functioning, and normalise brain activation (ie, a more focal activation of the sensorimotor network as observed in healthy controls) in pwMS.

H2: The effects of cued MI combined with cued gait training are superior to those of cued MI and cued gait training alone.

\section{METHODS AND ANALYSES}

\section{Study design, setting and timeline}

This study is designed as a multicentre, randomised, parallel, double-blind trial in pwMS with mild to moderate disability and follows the Standard Protocol Items: Recommendations for Interventional Trials (SPIRIT) 2013 and SPIRIT-PRO Extension Checklist (online supplemental file 1). Study results will be reported in accordance with the Consolidated Standards of Reporting Statement. ${ }^{35}$ The study will be conducted at the Clinical Department of Neurology, Medical Universities of Innsbruck (centre 1) and Graz (centre 3) and Clinic for Rehabilitation Muenster (centre 2), Austria. The expected recruitment phase is from 01 February 2021 to 31 March 2023.

\section{Patient and public involvement}

The study intervention was developed based on previous study results 27283637 and patient involvement. An MS advisory group was consulted to clarify any questions, for example, with respect to their music preference and suggestions for the duration of the imagined and actual gait training. Semi-structured telephone interviews will be used to gain insight into patients' problems with and acceptability of the intervention. Patients' acceptance of the intervention is essential for adherence.

\section{Sample size and participants}

The sample size for this study was calculated using previous study data ${ }^{27}$ and Cohen's d effect sizes of the walking distance endpoint, with 95\% CI and corrected estimates of pooled SD. Based on $80 \%$ power $(\beta=0.2)$, $\alpha=0.025$ and conservative effect sizes of $d=0.74$, a sample size of 37 participants per group is required to detect a between-group difference. Including $15 \%$ attrition and making the number divisible by 3 , a total sample size of 132 participants results. Thereof, 36 patients will also undergo MRI scanning, while 15 healthy controls will be enrolled to provide reference values for the MRI analyses. Study procedures including screening for eligibility are presented in online supplemental figure 1 (flow diagram).

Eligibility criteria for this study are listed in table 1.

\section{Recruitment, randomisation and blinding}

Information brochures and invitations for study participation will be displayed in the study centres 1-3 and on the Austrian MS Society website, with pwMS notified about the study by clinical department staff. Written informed consent will be obtained from all participants (see online supplemental file 2 for an English version of the patient information sheet and informed consent form). Healthy controls will be enrolled at centre 3 only.

Patients fulfilling the eligibility criteria will be randomised into one of three groups with stratified blocked randomisation performed by an independent researcher at centre 1 using an online software-based random number generator (Sealed Envelope, London, UK), blocks of prespecified size and 1:1:1 allocation. 
Table 1 Eligibility criteria

\begin{tabular}{|c|c|}
\hline People with MS & $\begin{array}{l}\text { Inclusion criteria } \\
\text { Any MS phenotype according to the revised McDonald's criteria }{ }^{123124} \\
\text { Aged } 18 \text { years or older } \\
\text { Any ethnicity } \\
\text { Disability status score on the Expanded Disability Status Scale (EDSS) }{ }^{41} \text { of } 2.0-5.0 \\
\text { Stable disease; no clinical evidence of disease activity } \\
\text { Ability to speak and understand German language } \\
\text { Exclusion criteria } \\
\text { Significant concomitant diseases (such as malignant diseases, other neurological or psychiatric } \\
\text { disorders, musculoskeletal problems affecting walking, pain, uncorrected visual or hearing impairment) } \\
\text { Cognitive impairment as defined by a MoCA cut-off score of } 26 / 30(<26=\text { impaired cognition) } \\
\text { - Anxiety or depression as signified by a HADS anxiety }{ }^{82} \text { or depression subscale score of } 11 / 21^{83} \text { or } \\
\text { suicidality as evaluated by a narrative screening } \\
\text { Pregnancy } \\
\text { Relapse of MS within the last } 3 \text { months before the study } \\
\text { Any medication initiation or change (including corticosteroids) or any physiotherapy change or inpatient } \\
\text { rehabilitation within } 3 \text { months prior to the study } \\
\text { Any change of symptomatic treatment affecting walking (medication or physiotherapy) or of disease } \\
\text { modifying treatment during the study will lead to an exclusion of the participant from further analysis }\end{array}$ \\
\hline Healthy controls & $\begin{array}{l}\text { Age-matched and gender-matched } \\
\text { Without any history of neurological, psychiatric or orthopaedic disorders }\end{array}$ \\
\hline $\begin{array}{l}\mathrm{MRl} / \mathrm{fMRl} \\
\text { contraindications }\end{array}$ & $\begin{array}{l}\text { Metallic or electricity conducting implants or prostheses (cardiac pacemaker, insulin pump, middle-ear } \\
\text { implants, heart valve or hip prostheses, artificial teeth, hearing aid, etc) in or on the body } \\
\text { Non-removable metal parts (coil, braces, etc) or metal shrapnel in or on the body } \\
\text { Tattoos in the head or neck area, nicotine plasters or cosmetic eye modifications } \\
\text { Pregnancy } \\
\text { Epilepsy } \\
\text { Claustrophobia }\end{array}$ \\
\hline
\end{tabular}

fMRI, functional MRI; HADS, Hospital and Anxiety and Depression Scale; MoCA, Montreal Cognitive Assessment; MS, multiple sclerosis.

Stratification will be performed according to relevant predictive factors for a change in walking that is, ${ }^{38}$ age $(<40$, $\geq 40$ ), gender (female, male) ${ }^{3940}$ and disability (Expanded Disability Status Scale ${ }^{41}$ 2.0-3.5, 4.0-5.0). Sequentially numbered sealed opaque envelopes including group allocation numbers for groups 1-3 will be fabricated for each stratum. Allocation concealment will be performed to avoid allocation bias, assessors blinded to participants' group allocation and participants unaware of the study hypotheses.

\section{Intervention}

Three intervention groups will receive home-based kinaesthetic MI and/or gait training with music, metronome and verbal cueing for a total of $30 \mathrm{~min}, 4$ times per week, for 4 weeks. Participants will receive cued MI (group 1), combined cued MI and gait training (group 2) or cued gait training (group 3).

An audio-mix has been created specifically for this study (Audacity. V.3.0.0) ${ }^{42}$ for download on participants' electronic devices or available as study CDs (group 1). Instrumental motivational music at a regular beat in a $2 / 4$ or $4 / 4 \mathrm{~m}$ and strong ON and OFF beat patterns (ie, with every first or first and third music beats stressed) will be utilised. ${ }^{6344}$ Additionally, metronome cues will accentuate the music beat and tempo and support gait synchronisation with the beat. Verbal cueing will be employed as a reminder of the task to practise and aid participants' focus on the respective body parts, for example, the feet.
Suitable rhythmical sequences at $80-120$ beats/min will be cut and mixed with instructions on MI or gait training. Rhythmic-verbal cues will accentuate the cueing intermittently, for example using 'step-step' or 'toe-off', ${ }^{45}$ with different walking tasks used. Familiarisation will occur individually with the rhythmic-cued MI and gait training as previously recommended..$^{21} 46$ The audio mix will be changed weekly to gradually increase the tempo and facilitate adherence. The PETTLEP approach to MI will be applied, involving the 'Physical, Environmental, Task, Timing, Learning, Emotional, and Perspective' components of MI. ${ }^{47}$ Using the Template for Intervention Description and Replication checklist, ${ }^{48}$ detailed information on the PETTLEP approach and intervention is provided in online supplemental table 1 . In figure 1, key aspects of the intervention are presented.

Practice frequency will be noted in a diary with weekly reports on participants' practice frequency prepared. Weekly phone calls will be used in the home-based training support of all participants, additionally at 4 weeks postintervention. Additional phone call support will be provided on request by the intervention providers. The content of the semi-structured telephone interviews during and postintervention is presented in figure 2 and online supplemental file 3 .

\section{Data collection}

Demographic and disease specific data will be collected as detailed in table 2 . Three categories of disease modifying 

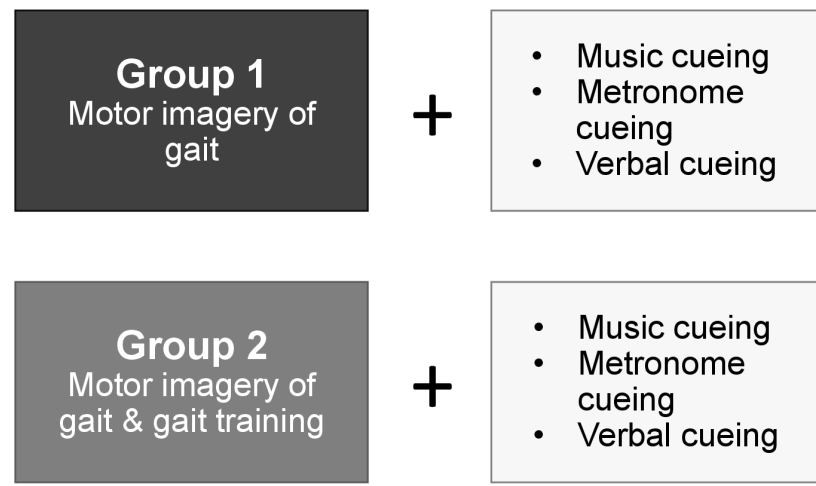

\section{$+$}

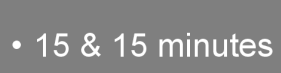

- 4 times/week

- for 4 weeks

- 30 minutes

- 4 times/week

- for 4 weeks
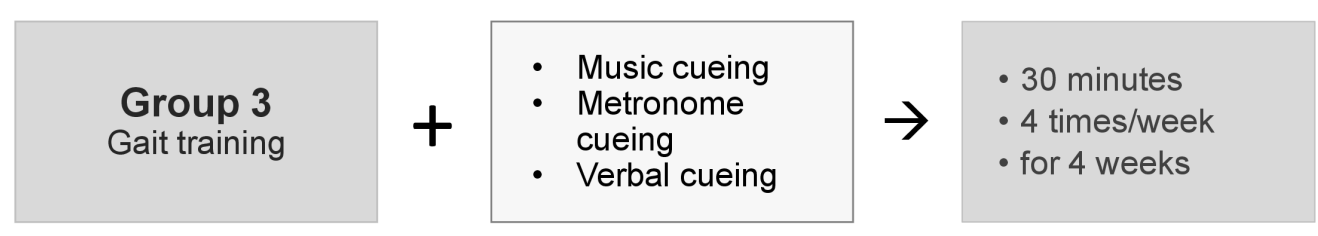

Figure 1 Key elements of the intervention in the three groups.

treatment (DMT) will be operationalised according to the disease activity and course (1) no DMTs; (2) moderately effective and (3) highly DMTs (active substances are detailed in table 2). DMTs will be recorded and handled as a covariate in the data analysis because they may affect the primary and secondary outcomes. Clinical data will be collected by trained and blinded assessors (physiotherapists, occupational therapists, sports scientists and psychologists), with the order of the patient-reported outcome measures being randomised for each participant and visit to minimise order effects. A schedule of the study procedures is provided in table 2 .

\section{Primary outcomes}

Primary outcomes are walking speed as assessed by the Timed 25-Foot Walk (T25FW) ${ }^{49}$ and walking distance as assessed by the 2-Minute Walk Test (2MWT). ${ }^{5051}$ For the T25FW, patients will be asked to walk a marked distance of 25 feet $(7.62 \mathrm{~m})$ as quickly as possible, though safely, with an assistive device as required. ${ }^{52}$ Scoring is achieved by taking the average of two trials. Excellent psychometric properties of the T25FW have been demonstrated. ${ }^{5354} \mathrm{~A}$ $20 \%$ change in the T25FW is interpreted as a clinically significant difference in walking speed. ${ }^{55}$

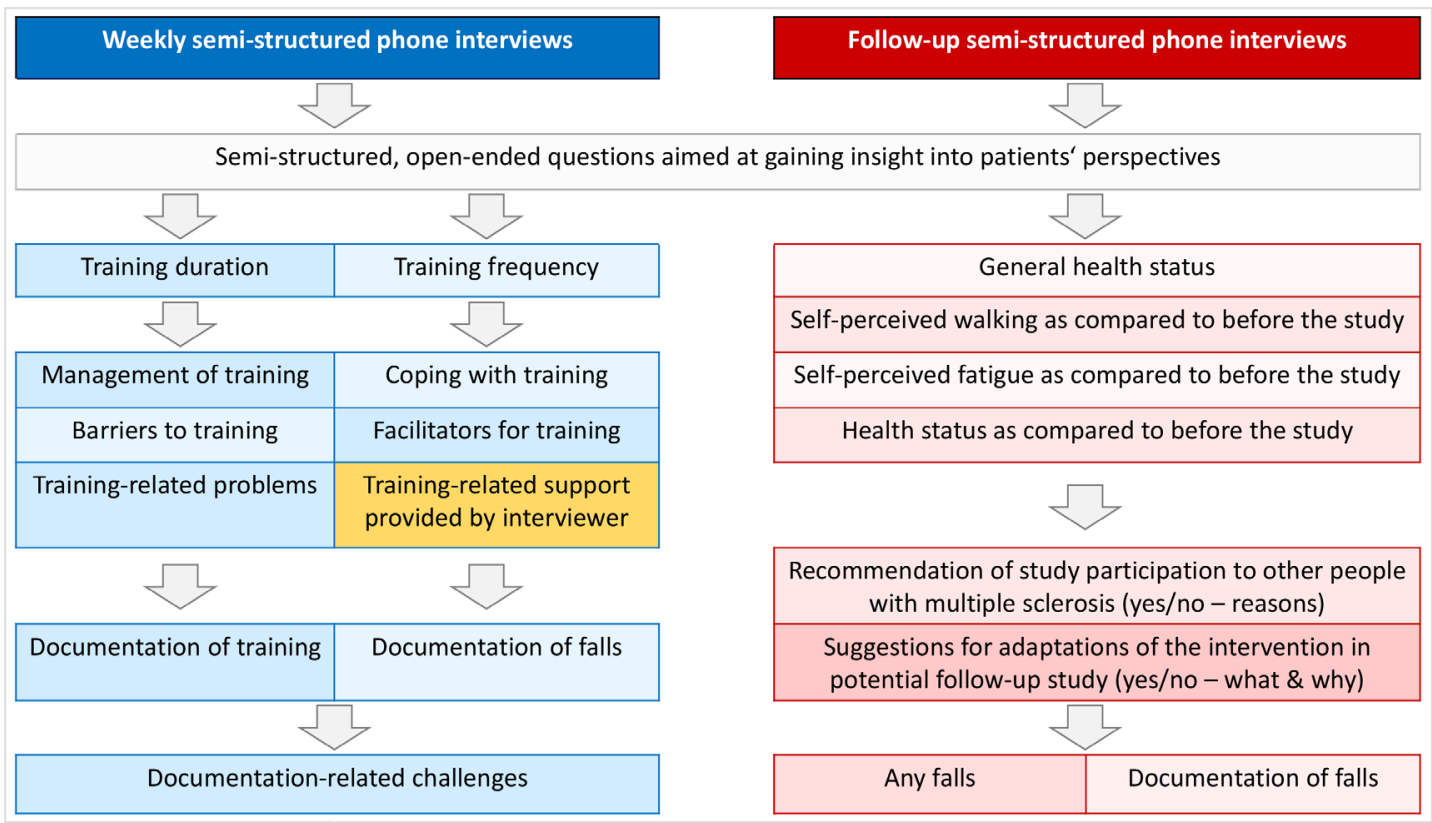

Figure 2 Content of semi-structured interviews. 
Table 2 Schedule of study procedures

\begin{tabular}{|c|c|c|c|c|c|c|}
\hline & \multicolumn{5}{|c|}{ Study period } & \multirow{3}{*}{$\begin{array}{l}\text { Follow-up } \\
\text { test } \\
\text { Month } 3\end{array}$} \\
\hline & \multirow{2}{*}{$\begin{array}{l}\text { Enrolment } \\
\text { Screening }\end{array}$} & \multirow[t]{2}{*}{ Allocation } & \multicolumn{3}{|l|}{ Postallocation } & \\
\hline & & & $\begin{array}{l}\text { Baseline test } \\
\text { Day } 1\end{array}$ & $\begin{array}{l}\text { Postintervention test } \\
\text { Week } 4\end{array}$ & $\begin{array}{l}\text { Follow-up phone call } \\
\text { Week } 8\end{array}$ & \\
\hline \multicolumn{7}{|l|}{ Enrolment } \\
\hline Eligibility screen & $x$ & & & & & \\
\hline \multicolumn{7}{|l|}{ Interventions } \\
\hline Music-cued MI group & & & 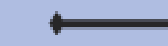 & $\longrightarrow$ & & \\
\hline \multicolumn{7}{|l|}{ Music-cued Ml and gait training group } \\
\hline Music-cued gait training group & & & $\longleftarrow$ & $\longrightarrow$ & & \\
\hline $\begin{array}{l}\text { Clinical characteristics (EDSS, MS phenotype, } \\
\text { disease duration, disease modifying treatment }{ }^{\star} \text { ) }\end{array}$ & $x$ & & & & & \\
\hline Global cognitive impairment (MoCA test) & $x$ & & & $x$ & & $x$ \\
\hline Anxiety and depression (HADS) & $x$ & & & $x$ & & $x$ \\
\hline Suicidality (narrative screening) & $x$ & & & $x$ & & $x$ \\
\hline \multicolumn{7}{|l|}{ Primary outcomes } \\
\hline Walking speed and distance (T25FW, 2MWT) & & & $x$ & $x$ & & $x$ \\
\hline \multicolumn{7}{|l|}{ Secondary outcomes } \\
\hline Brain activation patterns (fMRI) & & & $x$ & $x$ & & \\
\hline MS related fatigue (NFI-MS) & & & $x$ & $x$ & & $x$ \\
\hline Adverse events and adverse reactions (log) & & & & $x$ & $x$ & $x$ \\
\hline Falls (log) & & & & $x$ & $x$ & $x$ \\
\hline \multicolumn{7}{|l|}{$\begin{array}{l}\text { Acceptability of the intervention, adherence and } \\
\text { coping (checklist, weekly semi-structured phone } \\
\text { interviews) }\end{array}$} \\
\hline $\begin{array}{l}\text { Self-report health status and feedback on the } \\
\text { study intervention (follow-up semi-structured } \\
\text { phone interviews) }\end{array}$ & & & & & $x$ & \\
\hline
\end{tabular}

*Three categories of disease modifying treatment (DMT): (1) no DMTs; (2) moderately effective DMTs: interferon-b 1a and 1b, pegylated interferon-b 1a, glatiramer acetate, dimethyl fumarate, teriflunomide, azathioprine, intravenous immunoglobulins; (3) highly effective DMTs: alemtuzumab, cladribine, fingolimod, natalizumab, ocrelizumab, cyclophosphamide, mitoxantrone, rituximab, siponimod, ofatumumab and ozanimod. ${ }^{12}$

BMRI-2, Brunel Music-Rating Inventory-2; EDSS, Expanded Disability Status Scale; fMRI, functional MRI; HADS, Hospital Anxiety and Depression Scale; KVIQ-10, Kinaesthetic and Visual Imagery Questionnaire, short version; MI, motor imagery; MoCA, Montreal Cognitive Assessment; MS, multiple sclerosis; MusiQoL, Multiple Sclerosis International Quality of Life; 2MWT, 2 min Walk Test; NFI-MS, Neurological Fatigue Index-Multiple Sclerosis; SAM, Self-Assessment Manikin; SDMT, Symbol Digit Modalities Test; T25FW, Timed 25-Foot Walk; USE-MS, Unidimensional Self-Efficacy Scale for Multiple Sclerosis.

The 2MWT will be performed as outlined in the American Thoracic Society Guidelines, which were developed for the 6 min Walking Test ${ }^{56}$ and adapted by international experts from the NIH Toolbox. ${ }^{57}$ For the 2 MWT, excellent validity ${ }^{50}$ and test-retest reliability have been found ${ }^{59} \mathrm{~A}$ $20 \%$ change represents a clinically significant difference in walking distance. ${ }^{60}$

\section{Secondary outcomes}

Brain activation patterns

MRI data will be acquired at $\mathrm{T}_{1}$ and $\mathrm{T}_{2}$ on a 3 Tesla scanner (Siemens PRISMA, Siemens Healthcare Erlangen) using a 20-channel head coil. The MRI protocol includes a highresolution structural three-dimensional (3D) T1-weighted MPRAGE sequence with $1 \mathrm{~mm}$ isotropic resolution 
(repetition time $(\mathrm{TR})=1900 \mathrm{~ms}$, echo time $(\mathrm{TE})=2.7 \mathrm{~ms})$ and a T2-weighted sequence $(1 \mathrm{~mm}$ isotropic, $\mathrm{TR}=2800$ $\mathrm{ms}, \mathrm{TE}=405 \mathrm{~ms}$ ). A 3D fluid-attenuated inversion recovery (FLAIR) sequence $(1 \mathrm{~mm}$ isotropic, TR=5000 $\mathrm{ms}, \mathrm{TE}=393$ $\mathrm{ms}$ ) is administered to assess hyperintense T2-LL in patients. Additionally, diffusion tensor imaging (DTI; 1.5 $\mathrm{mm}$ isotropic, $\mathrm{TR}=3318 \mathrm{~ms}, 64$ directions), task-related fMRI ( $2 \mathrm{~mm}$ isotropic; TR=2500 ms; TE=30; 198 volumes, field of view $=192 \times 192 \mathrm{~mm}^{2}$, acquisition time $=8.31 \mathrm{~min}$ ) and resting-state fMRI ( $2 \mathrm{~mm}$ isotropic; TR=1000 ms; $\mathrm{TE}=35$; field of view $=256 \times 256 \mathrm{~mm}^{2}$, acquisition time $=5.20$ min) will be performed. The scans will take approximately $35 \mathrm{~min}$ in total.

\section{Task-related fMRI: experimental stimuli and procedure}

The block-fMRI task will comprise a music-cued bipedal ankle movement on a treadmill that is, alternating dorsiflexion and plantarflexion of both feet ${ }^{61}$ a corresponding music-cued MI, and a listen-to-music-only condition. Four instrumental music-excerpts were selected as cues based on the same criteria used in the interventions. ${ }^{6}$ Pace is held constant at 110 beats /min for all cues. Each condition is repeated four times, and presented in a pseudorandomised order, so that no condition or music-cue occurs twice in a row, and identical music-cues never run successionally.

Before each condition, a coloured symbol cue appears in the centre of the screen for $2.5 \mathrm{~s}$, indicating the subsequent condition (orange feet for movement, blue think bubble for MI, violet ear for music-only condition; figure 3A). At the start of each condition, a fixation cross in the corresponding colour appears and the music starts. Participants are instructed to perform the ankle movement at the pace of the music, starting with the right foot and concentrate on the music beat during the music-only condition. After $22.5 \mathrm{~s}$, the fixation cross turns black, indicating a period of total rest for $15 \mathrm{~s}$ (figure 3B).

Prior to entering the scanner, participants will practice the paradigm. Throughout the whole paradigm, participants are instructed to fixate on the cross, not to move their heads, to relax their entire body, except their feet during the movement condition. To decrease stimuluscorrelated motion, participants' heads are fixed with foam-cushions and their knees flexed to approximately $135^{\circ}$ using a soft roll and cushion beneath their knees (figure 3A) ${ }^{61}$ Vision is corrected with prism lenses if necessary. During the paradigm, participants are observed with correct and incorrect movements recorded. After the scan, participants are asked to complete a short questionnaire on whether they recognised the songs (yes/ no), liked the music-cues and found them motivating to move (both items: 7-point Likert scales). Three items will ask about the MI conditions (7-point Likert scale): the perceived MI difficulty and the extent to which they have 'seen' or 'felt' the MI (similar to the KVIQ-10 response format).

\section{Fatigue}

The Neurological Fatigue Scale-Multiple Sclerosis (NFIMS) will be used to assess fatigue, including subscales of physical and cognitive fatigue, relief through daytime sleep or rest and abnormal nighttime sleep and sleepiness. ${ }^{62} 63$ A summary score of items $1-7,9$ and 11-12 is generated. A 4-point Likert scale is used, from $0=$ 'strongly disagree' to $3=$ 'strongly agree', where higher scores represent more severe fatigue. The NFI-MS displayed good validity $^{63}$ and reliability. ${ }^{63}$

Health-related QoL

The 31-item Multiple Sclerosis International Quality of Life questionnaire (MusiQoL) ${ }^{64}$ has been chosen to record patient-reported health-related QoL (HRQoL). Nine dimensions of HRQoL are assessed: everyday activities, psychological well-being, symptoms, relationships with friends, family and the healthcare system, emotional and sex life, coping and rejection. A 5-point Likert scale from $1=$ 'never/not at all' to $5=$ =always/a lot' is used with reverse scoring of negatively worded items. Nine domain scores and the global index are standardised on a 0-100 scale, where 100 represents the best HRQoL. A good validity ${ }^{66}$ and reliability have been shown for the MusiQoL. ${ }^{64}{ }^{65}$

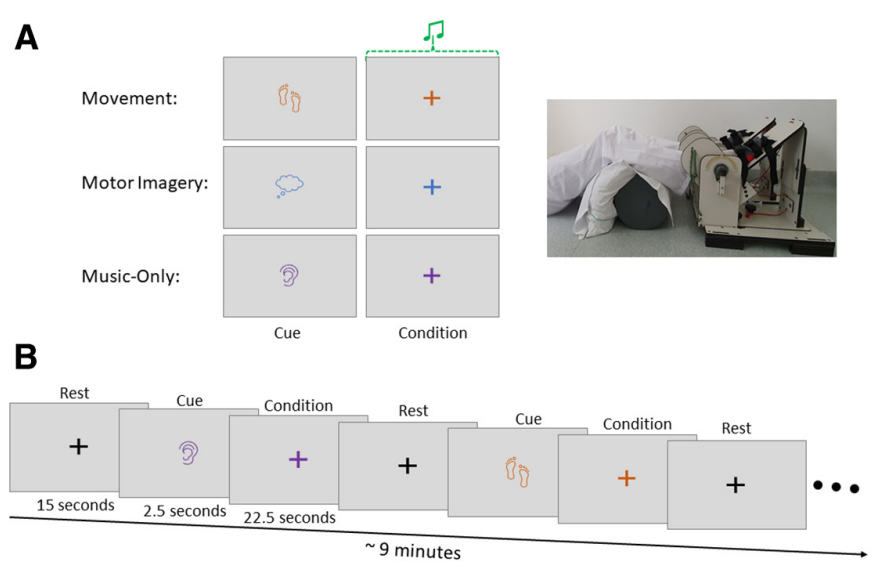

Figure 3 Schematic representation of the block functional MRI-paradigm. 


\section{Ml ability}

MI ability should be assessed using at least two different approaches ${ }^{67}$ hence the Kinaesthetic and Visual Imagery Questionnaire, ${ }^{68} 69$ using a German short version (KVIQG-10) ${ }^{68}$ and a mental chronometry (MC) test. ${ }^{70-72}$

The KVIQ- $(\mathrm{G}) 10$ is patient-reported and assessoradministered and measures visual and kinaesthetic MI ability in neurological patients using five items. ${ }^{69}$ Scoring is achieved using a 5-point Likert scale from 1='no image' to $5=$ 'image as clear as seeing' (visual subscale) and from $1=$ 'no sensation' to $5=$ 'as intense as executing the action' (kinaesthetic subscale). The KVIQ-G-10 has excellent psychometric properties. ${ }^{68}$

MC tests are based on the theory of functional equivalence between MI and actual movement. ${ }^{47} 73$ Excellent temporal equivalence has been found for corresponding imagined and real movements. ${ }^{72} \mathrm{MC}$ evaluation will be at a comfortable tempo on a marked 6-metre path. ${ }^{70-72}$ The 'index of deviation from isochrony' will be calculated to quantify the discrepancy between imagined and real walking: deviation index=absolute value $(1-(\mathrm{MI} / \mathrm{motor}$ execution).$^{76}$ Values close to zero are indicative of high MI ability. ${ }^{76}$

\section{Depression, anxiety and suicidality}

The German version ${ }^{77}$ of the Hospital Anxiety and Depression Scale (HADS) ${ }^{78}$ and narrative screening for suicidality $^{79}$ adapted from item 9 of the Beck Depression Inventory $^{80}$ and a suicidality screening checklist ${ }^{81}$ will be employed for screening. The 14-item HADS assesses patient-reported anxiety and depression during the previous 2 weeks. Anxiety or depression will be signified by a HADS anxiety ${ }^{82}$ or depression subscale score of $11 / 21$ points $^{83}$ or suicidality as evaluated by a narrative screening. ${ }^{79}$ Good validity, reliability ${ }^{84}$ and a bifactorial structure has been shown for the German HADS. ${ }^{77}$

\section{Overall cognitive impairment}

Overall cognitive impairment (attention and concentration, executive functions, memory, language, visuoconstructive abilities, conceptual thinking, arithmetic and orientation) will be assessed using the German Montreal Cognitive Assessment (MoCA). ${ }^{85} 86$ The highest possible score is 30 points; values $\geq 26$ are considered normal, ${ }^{87}$ with good psychometric properties demonstrated. ${ }^{87-89}$

\section{Motivational qualities of music in exercise settings}

The 6-item Brunel Music Rating Inventory-2 (BMRI-2) ${ }^{90}$ has been chosen to assess the music-induced motivation to move on a 7-point Likert scale. Music pieces selected from the audio-mix will be played to participants (in relevant $90 \mathrm{~s}$ excerpts). ${ }^{90}$ Motivational properties of the musical rhythm, style, melody, tempo, instrumentation and beat during physical exercise will be patient-rated. The BMRI-2 has shown good validity and reliability. ${ }^{901}$

\section{Music-induced pleasure and arousal}

The Self-Assessment Manikin (SAM) will be used to measure the emotional responses of pleasure and arousal to the music selected for the study intervention. ${ }^{92} 93$ The SAM consists of two series of pictograms, each of which displays a dimension on a 9-point scale. ${ }^{92} 93$ SAM validations have demonstrated good to excellent validity ${ }^{93} 94$ and reliability. ${ }^{95}$

\section{Self-efficacy}

The validated German version ${ }^{96}$ of the Unidimensional Self-Efficacy Scale for MS (USE-MS) ${ }^{97}$ will be used to assess self-efficacy. For this patient-reported 12-item questionnaire using a 4-point Likert scale, excellent psychometric properties have been seen. ${ }^{969}$

\section{Cognitive function}

Cognitive function including attention, visual scanning, working memory and psychomotor speed will be measured using the Symbol Digit Modalities Test (SDMT) ${ }^{98}$ Patients will be asked to assign the numbers 1 through 9 to nine different symbols within $90 \mathrm{~s}$. The number of maximum possible substitutions is 110 . Excellent construct, ${ }^{99}$ predictive ${ }^{100}$ and discriminatory validity ${ }^{101}$ and test-retest reliability $^{102}$ for the SDMT is demonstrated in pwMS.

\section{Falls, adherence, and acceptability of the intervention}

Falls and adverse events will be recorded in structured $\operatorname{logs}$, the relationship with the intervention evaluated and treatment provided if necessary, which is covered by an indemnity insurance policy. Semi-structured telephone interviews will gain information on adherence and acceptability. Adherence will be monitored using a selfreport checklist (figure 2).

\section{Data management}

As for confidentiality, the Austrian, Tyrolean and Styrian Data Protection Acts will be adhered to, and personal data codified by a participant ID. Only the research team will have access to the data. Data will be only used for the purposes for which they were collected and saved on a password-protected computer. Data will be digitised in double entry with double coding of interview data performed. Quality assurance measures such as spot checks of value ranges and field types and logical checks will be performed.

\section{Data analyses}

Statistical data analyses

All statistical analyses employ IBM SPSS software, release V.27.0 (IBM Corporation, Armonk, NY, USA) and GraphPad Prism V.9, San Diego, California, USA. A twotailed p value $<0.05$ will signify statistical significance. Using Little's test of missing completely at random (MCAR) the assumption of MCAR will be tested, signified by a $p$ value $>0.050 .{ }^{103}$ With data missing (completely) at random, multiple imputation will be used for handling missing data, or other strategies as appropriate. ${ }^{104}$ Including all cases as originally allocated, intention-to-treat analysis will be performed. Descriptive statistics will be used as appropriate and continuous data tested for normal distribution using the Shapiro-Wilk test, Q-Q-plots and histograms. 
For between-group comparisons at baseline, One-way analysis of variance (ANOVA), Kruskal-Wallis and $\chi^{2}$ tests will be used.

Mixed design ANOVA test assumptions will be tested for, for example, sphericity (Mauchly's test) and homogeneity of variance (Levene's test), and standard correction procedures applied where appropriate. For continuous variables (T25FW, 2MWT, MC and SDMT), a 2-way mixed design ANOVA will be conducted, using time as withinsubject factor and group as between-subject factor, and the three DMT categories as covariates (no DMT; moderately effective DMT; highly effective DMT) ${ }^{105}$ Post-hoc Bonferroni adjustment performed as appropriate. For categorical data (NFI-MS, MusiQoL, KVIQ-10, HADS, MoCA, BMRI-2, SAM and USE-MS), calculation of differences between postintervention and baseline values will be followed by Kruskal-Wallis and Dunn's multiple comparisons tests.

\section{Structural MRI analyses}

Using the Statistical Parametric Mapping-Lesion Segmentation Toolbox, T2-lesion load (T2-LL) will be assessed on T2-FLAIR images by the lesion prediction algorithm ${ }^{106}$ controlled by a single experienced rater. Individual binarised T2-LL masks will be registered to MNI and lesion probability mapping performed to identify the lesion locations, using FSL randomise. After lesion filling with the FSL lesion filling toolbox, brain volumes will be assessed from T1-weighted MPRAGE images using SIENAX.

\section{fMRI analyses}

Individual resting state and task-fMRI data will be preprocessed using FEAT (FMRIB's Expert Analysis Tool, V.6.0, part of FSL V.6.0. ${ }^{107}$ Preprocessing includes: motion correction using MCFLIRT, brain extraction, spatial smoothing using a Gaussian kernel of FWHM (full width at half maximum) of $5 \mathrm{~mm},{ }^{108}$ high pass temporal filtering using a cut-off of $150 \mathrm{~s}(0.007 \mathrm{~Hz})$, linear registration to main structural image (BBR) and non-linear registration warp resolution of $10 \mathrm{~mm}$. High-resolution T1 scans are used for image registration.

First-level task fMRI analyses will be performed for each participant, assessing activation patterns of the three conditions (movement, MI, music-only) and related contrasts. Higher-level analyses will be used to examine potential differences between intervention groups. Independent component analysis will be performed for rs-fMRI data (FSL-MELODIC, V.3.12). The resulting denoised functional images will be resampled to standard space (MNI152 template $2 \mathrm{~mm}$ ). Dual-regression analyses on the denoised, registered functional images of each subject will be performed to obtain individual spatial maps of the resting-state networks, focusing on the sensorimotor and salience network. Group functional connectivity maps for timepoints 1 and 2 and longitudinal change will be computed for each subject (using FSL Randomise).

\section{Qualitative data analysis}

A thematic analysis, understood as a 'method for identifying, analysing, and reporting patterns or themes within data ${ }^{109}$ of the interview material will be performed. ${ }^{110} 111$ Semantic and latent themes will be identified, summarised and interpreted, ${ }^{109}$ with data coded, segmented and extracted. From this data, broader themes will be developed. Themes will be reviewed, refined and validated in an iterative and reflexive process, ${ }^{112}$ data recoded as appropriate, and subthemes identified. Subthemes or categories will be judged by the criteria of internal homogeneity (meaningful coherence within a category) and external heterogeneity (clear differences between categories). ${ }^{113}$ The Consolidated criteria for Reporting Qualitative research will be followed to enhance rigour, credibility and reliability. ${ }^{114}$

\section{DISCUSSION}

This study will investigate the effects of three variants of home-based cued gait training interventions on walking, fatigue, emotional and cognitive function, and brain activation. Music will be included to both provide a temporal cueing to the real or imagined walking and potentially induce pleasure in practitioners. Pleasurable, motivating music is known to induce highly enjoyable emotions, motivation and arousal. ${ }^{115}$ Music-based interventions have been found to improve motor performance, mood and cognition in healthy people and patients with neurological disorders including MS. ${ }^{116117}$ This may be relevant because studies have further shown that depression ${ }^{118}$ and cognitive or higher levels of motor impairment ${ }^{119} 120$ reduce the MI ability in pwMS. Therefore, it seems relevant to include screening for anxiety, depression and cognitive impairment in the planned study. Moreover, other aspects, such as music-induced motivation, pleasure or arousal have not been previously measured in pwMS.

fMRI is a state-of-the-art method for assessing potential underlying mechanisms of motor impairment and rehabilitation. Despite the paucity of recent literature, we expect a training-induced decrease of the widespread activation, leading to a more focal activation of the primary sensorimotor network during the motor tasks. ${ }^{1-3}$ This would also be in line with previous research indicating a rehabilitation-induced 'normalisation' in brain activation, that is, activation patterns more similar to those observed in healthy controls. ${ }^{3}$ In accordance with previous studies, we expect that pwMS recruit similar brain areas during MI and actual movement, although sensorimotor regions might be activated to a lesser and premotor and parietal regions recruited to a higher extent during MI. ${ }^{121} 122$ Additionally, cued MI training may lead to similar reorganisation patterns compared with training of the actual movement. $^{34}$

The absence of a physiotherapist during the home-based intervention could be a potential limitation of this study. Using a thorough familiarisation to the music-supported MI and gait training, as well as regular telephone support, 
this limitation should be overcome. A further limitation could be a lack of motivation and adherence in participants, which we aim to counterbalance using weekly support phone calls and further support calls on request. A potential limitation in achieving the study objectives may be patients' hesitancy to undergo two extra MRI investigations at centre 3. Patients will be explained that they will be provided with the examination results at their request, which their treating doctors may include in their consultation and treatment planning.

Advantages of a home-based intervention are that pwMS can practise independently, provided that specifically trained physiotherapists familiarise them with the programme and guide their initial training phases. Depending on the results from this study, the most effective music-cued gait intervention can easily be put into practice.

\section{Author affiliations}

${ }^{1}$ Clinical Department of Neurology, Medical University of Innsbruck, Innsbruck, Austria

${ }^{2}$ Karl Landsteiner Institute for Interdisciplinary Rehabilitation Research, Münster, Austria

${ }^{3}$ Department of Neurology, Medical University of Graz, Graz, Austria

${ }^{4}$ Department of Neurology, Research Unit for Neuronal Plasticity and Repair, Medical University of Graz, Graz, Austria

${ }^{5}$ Department of Neurology, Clinic for Rehabilitation Münster, Münster, Austria

${ }^{6}$ Department of Radiology, Division of Neuroradiology, Vascular and Interventional Radiology, Medical University of Graz, Graz, Austria

${ }^{7}$ Department of Neurology; Division of Neuroradiology; Department of Radiology, Medical University of Graz, Graz, Austria

Acknowledgements The authors would like to thank patients in previous studies for their support and Professor Markus Reindl for helpful comments.

Contributors BS devised and designed the study, qualitative methodology and overall data analyses. FD, CB, CE and DP substantially contributed to the conception and design of the study. BS, DP and BH drafted the manuscript. DP, BH, SR and GR devised the MRI analyses. RE and $\mathrm{HH}$ provided substantial input on the study methodology. FD, CE and CB are study managers at their centres. All authors critically revised and approved the final manuscript.

Funding This is an academic study, which is conducted with the financial support of Celgene, a company of Bristol Myers Squibb (NA-CL-MS-PI-13909). The people involved in decision-marking about this funding have no influence on the study planning, conduct and publication.

Competing interests None declared.

Patient consent for publication Not applicable.

Provenance and peer review Not commissioned; externally peer reviewed.

Supplemental material This content has been supplied by the author(s). It has not been vetted by BMJ Publishing Group Limited (BMJ) and may not have been peer-reviewed. Any opinions or recommendations discussed are solely those of the author(s) and are not endorsed by BMJ. BMJ disclaims all liability and responsibility arising from any reliance placed on the content. Where the content includes any translated material, BMJ does not warrant the accuracy and reliability of the translations (including but not limited to local regulations, clinical guidelines, terminology, drug names and drug dosages), and is not responsible for any error and/or omissions arising from translation and adaptation or otherwise.

Open access This is an open access article distributed in accordance with the Creative Commons Attribution Non Commercial (CC BY-NC 4.0) license, which permits others to distribute, remix, adapt, build upon this work noncommercially, and license their derivative works on different terms, provided the original work is properly cited, appropriate credit is given, any changes made indicated, and the use is non-commercial. See: http://creativecommons.org/ licenses/by-nc/4.0/.
ORCID iD

Barbara Seebacher http://orcid.org/0000-0001-5699-9077

\section{REFERENCES}

1 Compston A, Confavreux C, Lassmann H. McAlpine's multiple sclerosis. 4 edn. London: Elsevier, 2006.

2 Induruwa I, Constantinescu CS, Gran B. Fatigue in multiple sclerosis - a brief review. J Neurol Sci 2012;323:9-15.

3 Krupp L. Fatigue is intrinsic to multiple sclerosis (MS) and is the most commonly reported symptom of the disease. Mult Scler 2006;12:367-8

4 Kamran F, Samaei A, Asghari N, et al. The associations between fatigue, disability, and mobility and the quality of life in patients with multiple sclerosis. Middle East $J$ Rehabil Health 2016;3:e34037.

5 Guillot A, Di Rienzo F, Macintyre T, et al. Imagining is not doing but involves specific motor commands: a review of experimental data related to motor inhibition. Front Hum Neurosci 2012;6:247.

6 Thaut MH. Rhythm, music and the brain. In: Scientific foundations and clinical applications. New York: Routledge, 2007: 272.

7 Thaut MH, Leins AK, Rice RR, et al. Rhythmic auditory stimulation improves gait more than NDT/Bobath training in near-ambulatory patients early poststroke: a single-blind, randomized trial. Neurorehabil Neural Repair 2007;21:455-9.

8 Hove MJ, Suzuki K, Uchitomi H, et al. Interactive rhythmic auditory stimulation reinstates natural $1 / f$ timing in gait of Parkinson's patients. PLoS One 2012;7:e32600.

9 Wittwer JE, Webster KE, Hill K. Music and metronome cues produce different effects on gait spatiotemporal measures but not gait variability in healthy older adults. Gait Posture 2013;37:219-22.

10 Cason N, Schön D. Rhythmic priming enhances the phonological processing of speech. Neuropsychologia 2012;50:2652-8.

11 Hausen M, Torppa R, Salmela VR, et al. Music and speech prosody: a common rhythm. Front Psychol 2013;4:566.

12 Baram Y. Virtual sensory feedback for gait improvement in neurological patients. Front Neurol 2013;4:138.

13 Uchitomi H, Ota L, Ogawa K-ichiro, et al. Interactive rhythmic cue facilitates gait relearning in patients with Parkinson's disease. PLOS One 2013;8:e72176.

14 Muto T, Herzberger B, Hermsdoerfer J, et al. Interactive cueing with Walk-Mate for hemiparetic stroke rehabilitation. J Neuroeng Rehabil 2012;9:58.

15 Conklyn D, Stough D, Novak E, et al. A home-based walking program using rhythmic auditory stimulation improves gait performance in patients with multiple sclerosis: a pilot study. Neurorehabil Neural Repair 2010;24:835-42.

16 Shahraki M, Sohrabi M, Taheri Torbati HR, et al. Effect of rhythmic auditory stimulation on gait kinematic parameters of patients with multiple sclerosis. J Med Life 2017;10:33-7.

17 Janata P, Tomic ST, Haberman JM. Sensorimotor coupling in music and the psychology of the groove. J Exp Psychol Gen 2012;141:54-75.

18 Jeannerod M. Mental imagery in the motor context. Neuropsychologia 1995;33:1419-32.

19 Kosslyn SM, Ganis G, Thompson WL. Neural foundations of imagery. Nat Rev Neurosci 2001;2:635-42.

20 Munzert J, Lorey B, Zentgraf K. Cognitive motor processes: the role of motor imagery in the study of motor representations. Brain Res Rev 2009;60:306-26.

21 Schuster C, Hilfiker R, Amft O, et al. Best practice for motor imagery: a systematic literature review on motor imagery training elements in five different disciplines. BMC Med 2011;9:75.

22 Jeannerod M. The cognitive neuroscience of action. Blackwell: Oxford, 1997.

23 Callow N, Hardy L. The relationship between the use of kinaesthetic imagery and different visual imagery perspectives. J Sports Sci 2004;22:167-77.

24 Guillot A, Collet C, Dittmar A. Relationship between visual and kinesthetic imagery, field dependence-independence, and complex motor skills. J Psychophysiol 2004:18:190-8.

25 Mohammadzadeh M, Haghgoo HA, Biglarian A, et al. Effects of combined mental and physical practices on walking and daily living activities in individuals with multiple sclerosis. IRJ 2020;18:455-64.

26 Kahraman T, Savci S, Ozdogar AT, et al. Physical, cognitive and psychosocial effects of telerehabilitation-based motor imagery training in people with multiple sclerosis: a randomized controlled pilot trial. J Telemed Telecare 2020;26:251-60.

27 Seebacher B, Kuisma R, Glynn A, et al. The effect of rhythmiccued motor imagery on walking, fatigue and quality of life in people 
with multiple sclerosis: a randomised controlled trial. Mult Scler 2017;23:286-96.

28 Seebacher B, Kuisma R, Glynn A, et al. Effects and mechanisms of differently cued and non-cued motor imagery in people with multiple sclerosis: a randomised controlled trial. Mult Scler 2019;25:1593-604.

29 Tavazzi E, Bergsland N, Cattaneo D, et al. Effects of motor rehabilitation on mobility and brain plasticity in multiple sclerosis: a structural and functional MRI study. J Neurol 2018;265:1393-401.

30 Hanson M, Concialdi M. Motor imagery in multiple sclerosis: exploring applications in therapeutic treatment. J Neurophysiol 2019;121:347-9.

31 Sandroff BM, Jones CD, Baird JF, et al. Systematic review on exercise training as a Neuroplasticity-Inducing behavior in multiple sclerosis. Neurorehabil Neural Repair 2020;34:575-88.

32 Bast T, Pezze M, McGarrity S. Cognitive deficits caused by prefrontal cortical and hippocampal neural disinhibition. $\mathrm{Br} J$ Pharmacol 2017;174:3211-25.

33 Prosperini L, Piattella MC, Giannì C, et al. Functional and structural brain plasticity enhanced by motor and cognitive rehabilitation in multiple sclerosis. Neural Plast 2015;2015:481574.

34 Vogt S, Di Rienzo F, Collet C, et al. Multiple roles of motor imagery during action observation. Front Hum Neurosci 2013;7:807.

35 Schulz KF, Altman DG, Moher D, et al. Consort 2010 statement: updated guidelines for reporting parallel group randomised trials. PLoS Med 2010;7:e1000251.

36 Seebacher B, Kuisma R, Glynn A, et al. Rhythmic cued motor imagery and walking in people with multiple sclerosis: a randomised controlled feasibility study. Pilot Feasibility Stud 2015;1:25.

37 Seebacher B, Kuisma R, Glynn A, et al. Exploring cued and noncued motor imagery interventions in people with multiple sclerosis: a randomised feasibility trial and reliability study. Arch Physiother 2018;8:6.

38 Baert I, Freeman J, Smedal T, et al. Responsiveness and clinically meaningful improvement, according to disability level, of five walking measures after rehabilitation in multiple sclerosis: a European multicenter study. Neurorehabil Neural Repair 2014;28:621-31.

39 Pau M, Casu G, Porta M, et al. Timed up and Go in men and women with multiple sclerosis: effect of muscular strength. J Bodyw Mov Ther 2020;24:124-30.

40 Røislien J, Skare Øivind, Gustavsen M, et al. Simultaneous estimation of effects of gender, age and walking speed on kinematic gait data. Gait Posture 2009;30:441-5.

41 Kurtzke JF. Rating neurologic impairment in multiple sclerosis: an expanded disability status scale (EDSS). Neurology 1983;33:1444-52

42 Audacity®. Version 3.0.0. Audio editor and recorder: Audacity Team; 2012 [It is free software distributed under the terms of the GNU General Public License. The name Audacity $®$ is a registered trademark.]. Available: http://audacityteam.org/ [Accessed 19 Nov 2020].

43 Thaut CP, Rice RR. Rhythmic auditory stimulation (RAS). In: Thaut $\mathrm{MH}$, Hoemberg V, eds. Handbook of neurologic music therapy. Oxford: Oxford University Press, 2014: 94-105.

44 Karageorghis Cl, Terry PC, Lane AM, et al. The bases expert statement on use of music in exercise. J Sports Sci 2012;30:953-6.

45 Edwards WH. Motor learning and control: from theory to practice. Belmont: Wadsworth, 2011.

46 Wondrusch C, Schuster-Amft C. A standardized motor imagery introduction program (MIIP) for neuro-rehabilitation: development and evaluation. Front Hum Neurosci 2013;7:477.

47 Holmes PS, Collins DJ. The PETTLEP approach to motor imagery: a functional equivalence model for sport PSYCHOLOGISTS. J App Sport Psychol 2001;13:60-83.

48 Hoffmann TC, Glasziou PP, Boutron I, et al. Better reporting of interventions: template for intervention description and replication (TIDieR) checklist and guide. BMJ 2014;348:g1687.

49 Kaufman M, Moyer D, Norton J. The significant change for the timed 25-foot walk in the multiple sclerosis functional composite. Mult Scler 2000;6:286-90.

50 Gijbels D, Eijnde BO, Feys P. Comparison of the 2- and 6-minute walk test in multiple sclerosis. Mult Scler 2011;17:1269-72.

51 Butland RJ, Pang J, Gross ER, et al. Two-, six-, and 12-minute walking tests in respiratory disease. Br Med J 1982;284:1607-8.

52 Cutter GR, Baier ML, Rudick RA, et al. Development of a multiple sclerosis functional composite as a clinical trial outcome measure. Brain 1999:122 (Pt 5:871-82.

53 Nieuwenhuis MM, Van Tongeren H, Sørensen PS, et al. The six spot step test: a new measurement for walking ability in multiple sclerosis. Mult Scler 2006;12:495-500.
54 Bosma LVAE, Sonder JM, Kragt JJ, et al. Detecting clinicallyrelevant changes in progressive multiple sclerosis. Mult Scler 2015;21:171-9.

55 Hobart J, Blight AR, Goodman A, et al. Timed 25-foot walk: direct evidence that improving $20 \%$ or greater is clinically meaningful in MS. Neurology 2013;80:1509-17.

56 A. T. S. Committee on proficiency standards for clinical pulmonary function laboratories. ats statement: guidelines for the six-minute walk test. Am J Respir Crit Care Med 2002;166:111-7.

57 Gershon RC, Wagster MV, Hendrie HC, et al. Nih toolbox for assessment of neurological and behavioral function. Neurology 2013;80:S2-6.

58 Gijbels D, Dalgas U, Romberg A, et al. Which walking capacity tests to use in multiple sclerosis? A multicentre study providing the basis for a core set. Mult Scler 2012;18:364-71.

59 Valet M, Lejeune T, Devis M, et al. Timed Up-and-Go and 2-minute walk test in patients with multiple sclerosis with mild disability: reliability, responsiveness and link with perceived fatigue. Eur $J$ Phys Rehabil Med 2019;55:450-5.

60 Learmonth YC, Dlugonski DD, Pilutti LA, et al. The reliability, precision and clinically meaningful change of walking assessments in multiple sclerosis. Mult Scler 2013;19:1784-91.

61 Enzinger $\mathrm{C}$, Johansen-Berg H, Dawes $\mathrm{H}$, et al. Functional MR correlates of lower limb function in stroke victims with gait impairment. Stroke 2008;39:1507-13.

62 NFI-MS Neurologischer Fragebogen zur Müdigkeit. NFI-MS Austria/ German - Version of 30 Sep 13 - Mapi ID7555 / NFI-MS_AU10_deuATdoc, 2010.

63 Mills RJ, Young CA, Pallant JF, et al. Development of a patient reported outcome scale for fatigue in multiple sclerosis: the neurological fatigue index (NFI-MS). Health Qual Life Outcomes 2010;8:22

64 Simeoni M, Auquier P, Fernandez $\mathrm{O}$, et al. Validation of the multiple sclerosis International quality of life questionnaire. Mult Scler 2008;14:219-30.

65 Flachenecker P, Vogel U, Simeoni MC, et al. [MusiQol: international questionnaire investigating quality of life in multiple sclerosis: validation results for the German subpopulation in an international comparison]. Nervenarzt 2011;82:1281-9.

66 Moore F, Vickrey B, Fortin K, et al. Two multiple sclerosis quality-oflife measures: comparison in a national sample. Can J Neurol Sci 2015;42:55-63.

67 Guillot A, Collet C. The neurophysiological foundations of mental and motor imagery. New York: Oxford University Press, 2010.

68 Schuster C, Lussi A, Wirth B, et al. Two assessments to evaluate imagery ability: translation, test-retest reliability and concurrent validity of the German KVIQ and Imaprax. BMC Med Res Methodol 2012;12:127

69 Malouin F, Richards CL, Jackson PL, et al. The Kinesthetic and visual imagery questionnaire (KVIQ) for assessing motor imagery in persons with physical disabilities: a reliability and construct validity study. J Neurol Phys Ther 2007;31:20-9.

70 Collet C, Guillot A, Lebon F, et al. Measuring motor imagery using psychometric, behavioral, and psychophysiological tools. Exerc Sport Sci Rev 2011;39:85-92.

71 Lee WH, Kim E, Seo HG, et al. Target-oriented motor imagery for grasping action: different characteristics of brain activation between kinesthetic and visual imagery. Sci Rep 2019;9:12770.

72 Papaxanthis C, Pozzo T, Skoura X, et al. Does order and timing in performance of imagined and actual movements affect the motor imagery process? the duration of walking and writing task. Behav Brain Res 2002;134:209-15.

73 Decety J, Grèzes J. Neural mechanisms subserving the perception of human actions. Trends Cogn Sci 1999;3:172-8.

74 Jeannerod $M$. The 25th Bartlett lecture. to act or not to act: perspectives on the representation of actions. $Q J$ Exp Psychol $A$ 1999;52:1-29.

75 Decety J, Jeannerod M, Prablanc C. The timing of mentally represented actions. Behav Brain Res 1989;34:35-42.

76 Marchesotti S, Bassolino M, Serino A, et al. Quantifying the role of motor imagery in brain-machine interfaces. Sci Rep 2016;6:24076.

77 Petermann Fet al. Hospital anxiety and depression scale, Deutsche version (HADS-D). Zeitschrift für Psychiatrie, Psychologie und Psychotherapie 2011;59:251-3.

78 Zigmond AS, Snaith RP. The hospital anxiety and depression scale. Acta Psychiatr Scand 1983;67:361-70.

79 Hanna J, Santo JB, Blair M, et al. Comparing depression screening tools in persons with multiple sclerosis (MS). Rehabil Psychol 2017;62:20-4

80 Beck AT, Ward CH, Mendelson M, et al. An inventory for measuring depression. Arch Gen Psychiatry 1961;4:561-71. 
81 Kozel B. Professionelle Pflege bei Suizidalität. 141. Köln: Psychiatrie Verlag, 2015.

82 Litster B, Fiest KM, Patten SB, et al. Screening tools for anxiety in people with multiple sclerosis: a systematic review. Int J MS Care 2016;18:273-81.

83 Watson TM, Ford E, Worthington E, et al. Validation of mood measures for people with multiple sclerosis. Int J MS Care 2014;16:105-9.

84 Herrmann C, Buss U, Snaith RP. HADS-D: ein Fragebogen Zur Erfassung von Angst und Depressivität in Der somatischen Medizin Testdokumentation und Handanweisung. Bern: Verlag Hans Huber, 1995.

85 Nasreddine ZS, Phillips NA, Bédirian V, et al. The Montreal cognitive assessment, MoCA: a brief screening tool for mild cognitive impairment. J Am Geriatr Soc 2005;53:695-9.

86 Bartusch S, Zipper S. Montreal cognitive assessment (MoCA), Deutsche Übersetzung, 2004. Available: www.mocatest.org [Accessed 2 Jan,2018].

87 Freitas S, Batista S, Afonso AC, et al. The Montreal cognitive assessment (MoCA) as a screening test for cognitive dysfunction in multiple sclerosis. Appl Neuropsychol Adult 2018;25:57-70.

88 Dagenais E, Rouleau I, Demers M, et al. Value of the MoCA test as a screening instrument in multiple sclerosis. Can J Neurol Sci 2013;40:410-5.

89 Sala G, Inagaki H, Ishioka Y. The psychometric properties of the Montreal cognitive assessment (MoCA): a comprehensive investigation. Swiss J Psychol 2020;79:155-61.

90 Karageorghis Cl, Priest D-L, Terry PC, et al. Redesign and initial validation of an instrument to assess the motivational qualities of music in exercise: the Brunel music rating Inventory-2. J Sports Sci 2006;24:899-909.

91 Clark IN, Baker FA, Peiris CL, et al. The Brunel music rating Inventory-2 is a reliable and valid instrument for older cardiac rehabilitation patients selecting music for exercise. Psychol Music 2016;44:249-62.

92 Lang PJ, Bradley MM, Cuthbert BN. International affective picture system (IAPs): technical manual and affective ratings, 1997.

93 Bradley MM, Lang PJ. Measuring emotion: the self-assessment manikin and the semantic differential. J Behav Ther Exp Psychiatry 1994;25:49-59.

94 Geethanjali B, Adalarasu K, Hemapraba A. Emotion analysis using SAM (self-assessment manikin) scale. Biomed Res 2017:S18-24.

95 Backs RW, da Silva SP, Han K. A comparison of younger and older adults' self-assessment manikin ratings of affective pictures. Exp Aging Res 2005;31:421-40.

96 Seebacher B, Mills RJ, Reindl M, et al. German translation, cultural adaptation and validation of the unidimensional self-efficacy scale for multiple sclerosis. BMC Neurol 2021;21:163.

97 Young CA, Mills RJ, Woolmore J, et al. The unidimensional selfefficacy scale for MS (USE-MS): developing a patient based and patient reported outcome. Mult Scler 2012;18:1326-33.

98 Smith A. Symbol digit modalities test (SDMT). manual (Revised). Los Angeles, CA: Western Psychological Services, 1982.

99 Benedict RHB, Cookfair D, Gavett R, et al. Validity of the minimal assessment of cognitive function in multiple sclerosis (MACFIMS). $J$ Int Neuropsychol Soc 2006;12:549-58.

100 Amato MP, Portaccio E, Goretti B, et al. Relevance of cognitive deterioration in early relapsing-remitting MS: a 3-year follow-up study. Mult Scler 2010;16:1474-82.

101 Benedict RH, DeLuca J, Phillips G, et al. Validity of the symbol digit modalities test as a cognition performance outcome measure for multiple sclerosis. Mult Scler 2017;23:721-33.

102 Benedict RHB. Effects of using same- versus alternate-form memory tests during short-interval repeated assessments in multiple sclerosis. J Int Neuropsychol Soc 2005;11:727-36.

103 Little RJA. A test of missing completely at random for multivariate data with missing values. J Am Stat Assoc 1988;83:1198-202.
104 Jakobsen JC, Gluud C, Wetterslev J, et al. When and how should multiple imputation be used for handling missing data in randomised clinical trials - a practical guide with flowcharts. BMC Med Res Methodol 2017;17:162.

105 Wiendl H, Gold R, Berger T, et al. [Multiple sclerosis treatment consensus group (MSTCG): position paper on disease-modifying treatment of multiple sclerosis 2021 (white paper)]. Nervenarzt 2021;92:773-801.

106 Schmidt $\mathrm{P}$, Pongratz V, Küster $\mathrm{P}$, et al. Automated segmentation of changes in FLAIR-hyperintense white matter lesions in multiple sclerosis on serial magnetic resonance imaging. Neuroimage Clin 2019;23:101849.

107 Jenkinson M, Beckmann CF, Behrens TEJ, et al. Fsl. Neuroimage 2012;62:782-90.

108 Poldrack RA, Mumford JA, Nichols TE. Handbook of functional MRI data analysis. Cambridge: Cambridge University Press, 2011.

109 Braun V, Clarke V. Using thematic analysis in psychology. Qual Res Psychol 2006;3:77-101.

110 Bree RT, Gallagher T. Using Microsoft Excel to code and thematically analyse qualitative data: asimple, cost-effective approach. AISHE-J 2021;8:6:2811-9.

111 Bree RT, Dunne K, Brereton B. Engaging learning and addressing over-assessment in the science laboratory: solving a pervasive problem. AISHE-J 2014;6.

112 Srivastava P, Hopwood N. A practical iterative framework for qualitative data analysis. Int J Qual Methods 2009;8:76-84.

113 Patton MQ. Qualitative evaluation and research methods. 2nd ed. Thousand Oaks, CA, US: Sage Publications, Inc, 1990.

114 Tong A, Sainsbury P, Craig J. Consolidated criteria for reporting qualitative research (COREQ): a 32-item checklist for interviews and focus groups. Int J Qual Health Care 2007;19:349-57.

115 Witek MAG, Clarke EF, Wallentin M, et al. Syncopation, body-movement and Pleasure in groove music. PLoS One 2014:9:e94446.

116 Sihvonen AJ, Särkämö T, Leo V, et al. Music-based interventions in neurological rehabilitation. Lancet Neurol 2017;16:648-60.

117 Karageorghis Cl, Terry PC. The psychological, psychophysical, and ergogenic effects of music in sport: a review and synthesis. In: Bateman AJ, Bale JR, eds. Sporting sounds: relationships between sport and music. London: Routledge, 2009: 13-36.

118 Tabrizi YM, Mazhari S, Nazari MA, et al. Abnormalities of motor imagery and relationship with depressive symptoms in mildly disabling relapsing-remitting multiple sclerosis. J Neurol Phys Ther 2014;38:111-8.

119 Tacchino A, Bove M, Pedullà L, et al. Imagined actions in multiple sclerosis patients: evidence of decline in motor cognitive prediction. Exp Brain Res 2013;229:561-70.

120 Heremans E, D'hooge A-M, De Bondt S, et al. The relation between cognitive and motor dysfunction and motor imagery ability in patients with multiple sclerosis. Mult Scler 2012;18:1303-9.

121 Hétu S, Grégoire M, Saimpont A, et al. The neural network of motor imagery: an ale meta-analysis. Neurosci Biobehav Rev 2013;37:930-49.

122 Hardwick RM, Caspers S, Eickhoff SB. Neural correlates of motor imagery, action observation, and movement execution: a comparison across quantitative meta-analyses. bioRxiv2017;198432.

123 Thompson AJ, Banwell BL, Barkhof F, et al. Diagnosis of multiple sclerosis: 2017 revisions of the McDonald criteria. Lancet Neurol 2018;17:162-73.

124 Polman $\mathrm{CH}$, Reingold SC, Banwell B, et al. Diagnostic criteria for multiple sclerosis: 2010 revisions to the McDonald criteria. Ann Neurol 2011;69:292-302.

125 Wiendl H, Gold R, Berger T, et al. Multiple sclerosis therapy consensus group (MSTCG): position statement on diseasemodifying therapies for multiple sclerosis (white paper). Ther Adv Neurol Disord 2021;14:17562864211039648. 